\title{
Energy Security and Scenario Analysis of Province One of Federal Democratic Republic of Nepal
}

\author{
Sujan Dulal ${ }^{1, *}$, Shree Raj Shakya ${ }^{1,2}$ \\ ${ }^{1}$ Department of Mechanical Engineering, Pulchowk Campus, Institute of Engineering, Tribhuvan University, Nepal \\ ${ }^{2}$ Center for Energy Studies, Institute of Engineering, Tribhuvan University, Nepal \\ Corresponding Email: sujandulal2009@gmail.com
}

\begin{abstract}
:
This paper presents the current energy security status of the Province One of Federal Democratic Republic Nepal using numerous indicators. In addition to that, with the development of five economic growth scenarios i.e. Normal growth (NOR) $(5.80 \%)$, Low growth (LOW) (4.20\%), High growth (HIG) (6.80\%), Accelerated growth (ACC) (8.50\%), and Intervention scenario (INT) on Normal growth scenario (NOR), the future energy mix and energy security indicators for the year 2040 are also calculated. The thesis also gives an overview of the variation/progress of the different indicators during the considered period of study (2017-2040). On the basis of compilation of data published by Water and Energy Commission Secretariat (WECS) and use of model developed in Long Range Energy Alternative Planning (LEAP), the study shows the increase in demand of the final energy consumption of province in Normal growth scenario to 101.8 million GJ at 2040 from 80.2 million GJ at 2017, whereby residential sector being the largest energy consuming sector with share of $68 \%$ in the total energy mix. However, the energy consumption increases to only 86.8 million GJ at the end year in the Intervention scenario. Similarly, the electricity consumption/demand increases by $120 \%$ and $390 \%$ in the normal and intervention economic growth scenario respectively. The study also shows that the, energy intensity in the intervention scenario is brought down to $4.44 \mathrm{GJ} / \mathrm{USD} 1000$ compared to that of $15 \mathrm{GJ} / \mathrm{USD} 1000$ in the base year. Also, the electricity consumption per capita is increased to $574 \mathrm{kWh}$ from $116 \mathrm{kWh}$ in the base year in INT scenario. Moreover, the GHG emission in the normal growth scenario at the end year will be $592.8 \mathrm{~kg} /$ Capita i.e. $59.5 \%$ increase from the base year. However, with the intervention scenario adopted, the GHG emission can be limited to only $385.2 \mathrm{~kg} /$ Capita in the end year, which is $8 \%$ increase from the base year value of $371.8 \mathrm{~kg} / \mathrm{Capita}$. However, these values are only achieved if the provincial government helps implementing federal government's plan of promoting the renewable energy systems and technologies instead of traditional fuel woods and fossil fuels system.
\end{abstract}

Keywords: Energy Mix, Fuel Mix, Energy Security, Province Level, Indicators, LEAP, Scenario, Policy Intervention

\section{Background}

The Constitution of Nepal, 2015 has restructured the nation into a Federal Democratic Republic and has divided the nation into seven provinces [1]. Along with that, various targets and milestones have been set by the government on the federal level to be met /achieved in different time frames within the upcoming few decades [2]. So, the strategies and vision of the federal level will definitely influence and effect the policy and planning of the provinces. Moreover, in reverse the work plan and policies of the provinces must also be so as to comply with the federal level targets. Hence, now onwards the prosperity and development of the provinces will mainly depend on its own management of the available resources. The issues of the energy security will be of significant importance for the province's economic boom. Simultaneously, the provinces also have to work on the optimum utilization of its available resources in order to make it self-sustainable in the long run. As we know, energy mix is very helpful in understanding the current energy status and energy balance of the country [3]. In addition to that, the energy security indicators deduced from those energy data will further elaborate the scenario, which can eventually be used as a resource for drafting policies and action plans for the energy sector improvement leading to energy sustainability of the province. Although, there are some works done in this area of research, the number of indicators used is very limited. So, there is still some room for doing study of the energy mix and energy security using a larger number of applicable indicators. Also, it has not been that long the province division has been carried out, there is no any study conducted on the provincial level for the energy mix and energy security scenario. Thus, the energy mix and scenario analysis of the province would help to have a better picture of the energy security status of that region and can serve as a value addition for the province's energy 
planning and policy making. The methodology which is used in doing the study of the Province One can serve as a good resource for conducting similar kind of study for other provinces/regions as well.

\subsection{Overview of current status of Energy Mix of Province One}

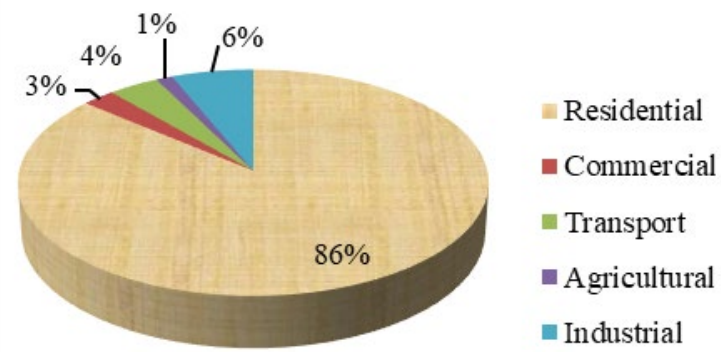

Figure 1: Current sector wise Energy Mix of Province 1 [4]

The total energy consumption in Province One in the year 2017 is 80.19 Million GJ. Energy is mostly consumed in five sectors i.e. Residential, Commercial,

Transport, Agriculture and Industrial. Among them, residential sector consumes 69 million gigajoule of energy occupying a share of $86.10 \%$ in the total energy consumption. After residential, industrial and transport sectors are the large energy consuming sectors having the share of $6.30 \%$ and $4.00 \%$ in the total energy consumption respectively. Whereas, commercial and agricultural sectors are the least energy consuming sectors having only $2.51 \%$ and $1.31 \%$ share in the total energy mix respectively.

There is diverse range of fuels which are being supplied and used for meeting the various energy demands of different sectors in the province. However, fuel wood is the most commonly used fuel type (mostly in residential sector) having a share of almost $74.01 \%$ in the fuel mix of the whole province. Similar to the fuel wood, animal waste and biomass are also widely used as the fuel because of the huge abundance in the surrounding.

Although, the hydropower potential of the region is quite high, it has not been largely exploited and thus electricity only accounts for $2.52 \%$ share in the total fuel mix of the province.

Moreover, imported fuels like gasoline, diesel are important fuels for the transport sector. Similarly, other fossil fuels like coal and petroleum coke are essential requirement in industries. Thus, the share of fossil fuels in the total fuel mix of the region stands at about $10.00 \%$.

\section{Literature}

Issues related to energy sector have been the hot topic of discussion for the past 10-15 years now. There are numerous reports and papers published during that time frame suggesting the possible causes and its possible solutions for the crisis. Every sector of economy i.e. commercial, industrial, etc. have been deeply affected by the energy crisis resulting in the slow paced economic development of the nation.

The various reports published in different point of time such as Nepal's Energy Vision 2050 [2] and National Survey of Energy Consumption and Supply in Nepal [4] provide information for the development of the different future scenarios. Energy Demand Projection 2030 [5] and all those reports have been referred for the projections of the energy mix.

National Energy Strategy of Nepal [3] highlights the major resources that are used for fulfilling the various needs of cooking, lighting, heating, transport and electrification of different domestic, commercial and industrial sectors. For making the strategy, it has developed mainly three scenarios i.e. Business as Usual, Reference Case as per Interim Plan and High Growth/Accelerated Growth Scenario. And, there is the comparison among the results and outcomes that can be realized in the future based on the respective assumptions and scenario development.

The report Electricity Demand Forecast Report [6] describes about the current status of electricity generation, transmission and distribution. Model for Analysis of Energy Demand (MAED) is used for projecting the electricity demand up to 2040. MAED evaluates future energy demand based on a set of consistent assumptions on medium to long term socio-economic, technological and demographic developments in a country or a region. Future energy needs are linked to: (i) the production and consumption of goods and services; (ii) lifestyle changes caused by increasing personal incomes; and (iii) mobility needs, etc. Energy demand is computed for a host of end use activities for three main "demand sectors": household, services, industry and transport. MAED provides a systematic framework for mapping trends and anticipating change in energy needs, particularly as they correspond to alternative scenarios for socioeconomic development. The collected data were reconstructed to make compatible for input in MAED Model.

For the Energy Demand Analysis, three different scenarios were prepared considering GDP growth rates of $4.50 \%, 7.20 \%$ and $9.20 \%$. These Business as Usual, Reference and economic growth rates are assumed 
analyzing the past growth rates and the targets set out by the government through various plan documents.

The District Climate and Energy Plan of Sunsari [7] helps to disaggregate the size of study to the district level. The overall objective of the task was to prepare a district climate change adaptive, de federalized renewable energy plan that presents a detailed implementation plan which contributes to climate change mitigation as well as adaptation and addresses the mainstreaming of Gender Equality and Social Inclusion. The data that were collected from the field as well as secondary published sources were used to develop the Business as Usual scenario (BAU), where current trends of energy use and technology intervention were assumed to continue. All the up-to-date RETs intervention levels were incorporated into the data so as to provide the current up-date information. Following this, two further scenarios such as Medium Adaptation Scenario (MAS) and a Climate Resilient Scenario (CRS) were developed.

\subsection{Energy Security}

In literal meaning, the term energy security itself looks self-explanatory. However, there are numerous definitions of energy security provided by different organizations and agencies. In general terms, energy security for the developing countries refers to enough energy supply to meet all requirements at all time of its citizens in affordable and stable prices [8]. Whereas, for developed nations, energy security refers to resilient energy system and securing the amount of energy required for people's life, economic and social activities, defense and other purposes for acceptable prices [8]. Although, there are no any standard definition, among various definitions of energy security, the one presented by the International Energy Agency is widely applied, which is defined as "the uninterrupted physical availability of energy at a price which is affordable, while respecting environment concerns" [9].

Although there are not much academic literatures for the provincial energy security context, several studies and research have been done in global, regional and national levels throughout the world. Aized et al [10] conducted an analysis of renewable energy policies of Pakistan and its implications on the energy security of the country. It also highlighted that the basis of those policies rest on energy security and self-sufficiency, social equity and economic benefits.

Matsumoto and Shiraki [11] evaluated energy security performance in Japan under alternative scenarios of future socioeconomic and energy conditions by applying three energy security indicators derived from the ShannonWiener diversity index. It also discussed that the Strategic Energy Plan of Japan 2014 developed after the Fukushima Nuclear disaster prioritizes energy security by also considering the economic efficiency and environment conservation with a strong focus on safety. It also emphasized that the economic growth with renewable energy use and energy savings will definitely improve the energy security of the country. In addition, Kitamura and Managi [12] suggested that in the case of supply disruption of fossil fuels in Japan, nuclear power generation and renewable energy power generation can mitigate the impact of energy resource supply interruption in the power generation sector. However, they hinted a significant effect in the customer sector due to supply interruption of Liquefied Natural Gas.

The study done on assessment of Indonesia's energy security performance conceptualized energy security in five dimensions: availability, affordability, accessibility, acceptability and efficiency by further composing fourteen indicators based on those dimensions [13]. It also analyzed and suggested that the energy security of Indonesia is in increasing trend from 2008 to 2013 and stands at number 55 among 71 countries compared in terms of energy security performance. Similarly, in a study conducted for comparing national energy security policies and its performance among countries like United States, European Union, Australia, New Zealand, China, India, Japan, South Korea, and the ten countries comprising the Association of Southeast Asian Nations (ASEAN), it argued that energy security needs to be comprised of five dimensions related to availability, affordability, technology development, sustainability, and regulation [14]. Furthermore, it suggested that trying to measure energy security by using only single metrics in isolation such as energy intensity, the rate of electrification, or electricity consumption per capita, provides an incomplete and possibly misleading assessment.

Kisel et al [15] challenged the viability of some of the energy security methodologies used from the publicly available indicators database and based on the experience of high-level energy policymaking in Estonia have introduced new indicators through Energy Security Matrix that would deliver stronger energy security policy for any state. Similarly, another study suggests that the Aggregated Energy Security Performance Indicator (AESPI) can be used as baseline of energy security for a region as it can show the pathway of current policies/measures, trends in the future, and also the 
pathway of alternate scenarios of new policies assessments [16]. It also presented a case study of Phuket, a province of Thailand, which had low AESPI compared to the national level can be gradually improved by by promoting electricity conservation, energy efficient equipment use and cost-effective renewable energy projects.

A study conducted for analyzing the role of renewable energy in China's energy security and climate change mitigation points that the country for the first time, translated into a net importer of coal, and the dependency of oil import was about 53\% [17]. Thus, through the development of national plan for coping with climate change 2014 and Twelfth Five-Year Plan for National Strategic Emerging Industries Development, China has declared to renewable source as the new source for economic growth. Also, renewable energy is not only taken as a sustainable choice of clean energy system, but also as an approach to addressing other social pressing needs, including improving energy security, reducing environmental impacts associated with fossil fuel consumption, as well as mitigating climate change [17].

Energy security in countries with very limited indigenous resources, the nature of economy is decisive factor in shaping the policies for security of energy supply and is mostly viewed from the perspective of vulnerability, efficiency and sustainability [18]. Due to the common unique characteristics in the economy, society, and especially in the energy import dependence and lack of indigenous energy resources, the advanced island economies tend to focus on increasing the ratio of nation's controllable energy resources including self-developed fossil fuels, renewable energies, and nuclear power $[11,18]$. In the case of association of different nations like Association of Southeast Asian Nations (ASEAN), the concept of regional self-reliance could be useful because despite of uneven economic and energy development, existing intra-regional energy markets are interconnected and ASEAN can enhance the energy security and sustainability by promoting regional cooperation in the field of energy [19].

For the context of Nepal, scenario analysis performed suggests that with high electrification and energy efficiency and demand-side management, all three major goals of sustainable energy for all can be achieved by 2030, but with total discounted systems costing three times the cost required in the case of Business As Usual scenario [20,21]. And Shakya and Shrestha [22] emphasizes on transport sector electrification for decreasing the Oil consumption per capita and reducing the dependence on imported fuels eventually limiting the production of GHG emissions significantly.

\subsection{Energy Security Indicators}

Some of the energy security indicators were also highlighted in the reports of District Climate and Energy Plan [7] and Water and Energy Commission Secretariat [2] .Those compiled ten indicators are Final Energy Consumption per Capita (GJ/Capita), Electricity Consumption per Capita (kWh/Capita), Energy Intensity (GJ/USD1000), Electricity Intensity (kWh/USD1000), Electricity Generated Power Utilized (Percent), Total Energy Consumption/Value Added in Industrial Sector (GJ/USD1000 Value added), Total Energy Used/ Household $(\mathrm{GJ} / \mathrm{HH})$, Share of renewable energy in final total energy consumption (Percent), The ratio of net import to total primary energy supply (Percent), and GHG emission for every ton of energy production and use/capita (GHG in kg/Capita).

Apart from those vision and strategy documents, some national and international papers and reports highlights and explains about the different indicators that help to understand the energy security status of a certain region in a more critical manner. Kruyt et al. [23] discusses about the different dimensions and themes of the energy security indicators:

\section{a) Availability-geological existence}

Primary sources of energy are the found in nature and its abundance solely depends on the geology of the particular region, which eventually determines the quantity and quality of availability.

\section{b) Accessibility-geopolitical elements}

Ease of access to the source is an important dimension of energy security. Infrastructures and roads for the extraction of the resources is vital for processing and using it for meeting the energy demands.

\section{c) Affordability- economical elements}

Price to be paid for meeting the energy demand is another important dimension of the security. In addition to being available and accessible, the resource should be affordable and should be within the purchasing capacity of people of the region.

\section{d) Acceptability, environmental and societal elements}

Issues of emissions, health hazards, etc. of the energy resource can lead to the unacceptability and reluctance in the end use. And on the basis of those dimensions, it 
suggests some indicators like Resource Estimates, Resource estimates, Import dependence, Political stability, Energy Price, Shannon Index, Supply/Demand Index, and Willingness to pay and Oil vulnerability Index.

Martchamadol and Kumar [24] discussed about the indicators based on different themes as compared to Kruyt, et al [23]. It has categorized the indicators into four basic themes for example, Energy Demand, Availability of Energy Supply, Energy Market, and Energy Price. Furthermore, it suggested four indicators on the basis of these dimensions namely, Net Energy Import Ratio (NEIR), Shannon-Weiner Index (SWI), HerfindhalHirshman Index (HHI), and Reserve to Production Ratio.

Similarly, a report from Asia Pacific Energy Research Council [25] highlights a different set of indicators namely, Diversification of Primary Energy Demand (DoPED), Net Energy Import Dependency (NEID), NonCarbon Intensive Fuel Portfolio (NCFP), and Net Oil Import Dependency (NOID).

Those papers and reports were mainly focused for international context. However, Shakya and Shrestha [22] highlighted and narrowed down some of the indicators useful in the context of Nepal such as:

\section{a) Shannon-Wiener Index (SWI)}

It describes about the diverseness of energy resources. Its value ranges 0 to 2 . So, more the value, more diverse the energy resources are.

\section{b) Net Energy Import Ratio (NEIR)}

It shows the regions status; either it is an energy exporting or an importing region. Positive value indicates the region's status to be an energy importing, whereas negative value indicates the energy exporting status of the region.

\section{c) Oil Consumption per Capita (OCPC)}

It shows the dependence of fossil fuels. For the oil importing countries like Nepal, lesser the value, better the energy security performance.

All of these indicators highlighted in the international and regional literatures may not be relevant in the context of Nepal and eventually to the context of Province One. Thus, sixteen energy security indicators as suggested in the literature of Asian countries for example, WECS, APERC and ASEAN are used for this study.

- $\quad$ Final Energy Consumption per Capita (GJ/Capita)

- Electricity Consumption per Capita (kWh/Capita)

- $\quad$ Energy Intensity (GJ/USD1000)
- $\quad$ Electricity Intensity (kWh/USD1000)

- $\quad$ Electricity Power Utilized (Percent)

- Total Energy Consumption/Value Added in Industrial Sector (GJ/USD1000 Value added)

- Total Energy Used/ Household (GJ/HH)

- Share of renewable energy in final total energy consumption (Percent)

- The ratio of net import to total primary energy supply (Percent)

- $\mathrm{GHG}$ emission for every ton of energy production and use/capita (GHG in kg/Capita)

- $\quad$ Net Energy Import Ratio (NEIR)

- Shannon-Weiner Index (SWI)

- $\quad$ Net Oil Import Dependency (NOID)

- $\quad$ Net Energy Import Ratio (NEIR)

- Oil Consumption per Capita (OCPC)

- Oil Consumption per unit GDP in USD

\subsection{Sustainable Development Goals}

Sustainable Development Goals, also known as the global goals, are a universal call to action for transforming the world through sustainable development [26]. One hundred and ninety three nations have adopted these global goals set by the United Nations to be achieved by 2030. It consists of seventeen thematic goals, out of which the goal number seven highlights about the affordable and clean energy. Some figures represented in the SDG's are:

- One in five people still lacks access to modern electricity.

- Three billion people rely on wood, coal, charcoal or animal waste for cooking and heating.

- Energy is the dominant contributor to climate change, accounting for around 60 per cent of total global greenhouse gas emissions.

- Reducing the carbon intensity of energy is a key objective in long-term climate goals.

Sustainable Energy for All initiative is being led by UN based on goal seven of the SDG's to ensure universal access to modern energy services, improve efficiency and increase use of renewable sources [26]. The targets set under the initiative are:

- By 2030, ensure universal access to affordable, reliable and modern energy services.

- By 2030, increase substantially the share of renewable energy in the global energy mix.

- By 2030, double the global rate of improvement in energy efficiency.

- By 2030, enhance international cooperation to facilitate access to clean energy research and 
technology, including renewable energy, energy efficiency and advanced and cleaner fossil-fuel technology, and promote investment in energy infrastructure and clean energy technology.

- By 2030, expand infrastructure and upgrade technology for supplying modern and sustainable energy services for all in developing countries, in particular least developed countries, Small Island developing States, and land-locked developing countries, in accordance with their respective programs of support.

\section{$2.4 \quad$ Energy Situation of Nepal}

In the present context, the energy consumption in Nepal is 489 Million GJ, traditional sources like fuel wood, biomass, contributing the largest share [27,28]. However, if we see the energy production, only 411.6 million GJ is produced, and the rest 81.57 Million GJ of energy is being imported for meeting the energy demand. The fossil fuels have the largest share in the energy import, since the country doesn't have fossil fuel resources, in order to meet the demand of gasoline, diesel and coal in mainly transportation and industrial sector. As per the reports, Nepal imported 402,277 KL of gasoline and 1,297,066 KL of diesel for meeting the transport sector demand [29]. Regarding the electricity status of the country, Nepal Electricity Authority has the total installed capacity of 972 MW, and out of which about $967 \mathrm{MW}$ is connected to the national grid and about 4.5 MW of electricity is isolated [30]. Energy consumption per capita of the country is $17.15 \mathrm{GJ}$ which is 4.5 times less than the world average. However, the energy consumption per USD1000 GDP is $24.68 \mathrm{GJ}$, which is almost twice the world average value $[27,28]$. Similarly, the electricity consumption per capita of about $140 \mathrm{kWh}$, which is significantly low compared to other, for example, China has $4050 \mathrm{kWh} / \mathrm{capita}$, India has $860 \mathrm{kWh} / \mathrm{capita}$ and the world average of 3000 $\mathrm{kWh} /$ capita. However, in terms of emissions, the value is 12 times lower than the world average value of 4400 $\mathrm{kg} / \mathrm{capita}$. Similarly breaking down those energy data for the Province One, the import of gasoline is $70,709 \mathrm{KL}$ and of diesel is $227,383 \mathrm{KL}$ [29]. Similarly, among $972 \mathrm{MW}$ of installed capacity of hydropower plants, Province One has 118.5 MW of installed capacity for the electricity generation. Moreover, $671 \mathrm{MW}$ of hydropower plant are in construction phase, whereas $835 \mathrm{MW}$ of hydropower plant are in planning phase in province [30].

\section{Methodology}

\subsection{Methodological Flowchart}

The methodology followed for doing the study can be understood from the flowchart drawn and the explanations.

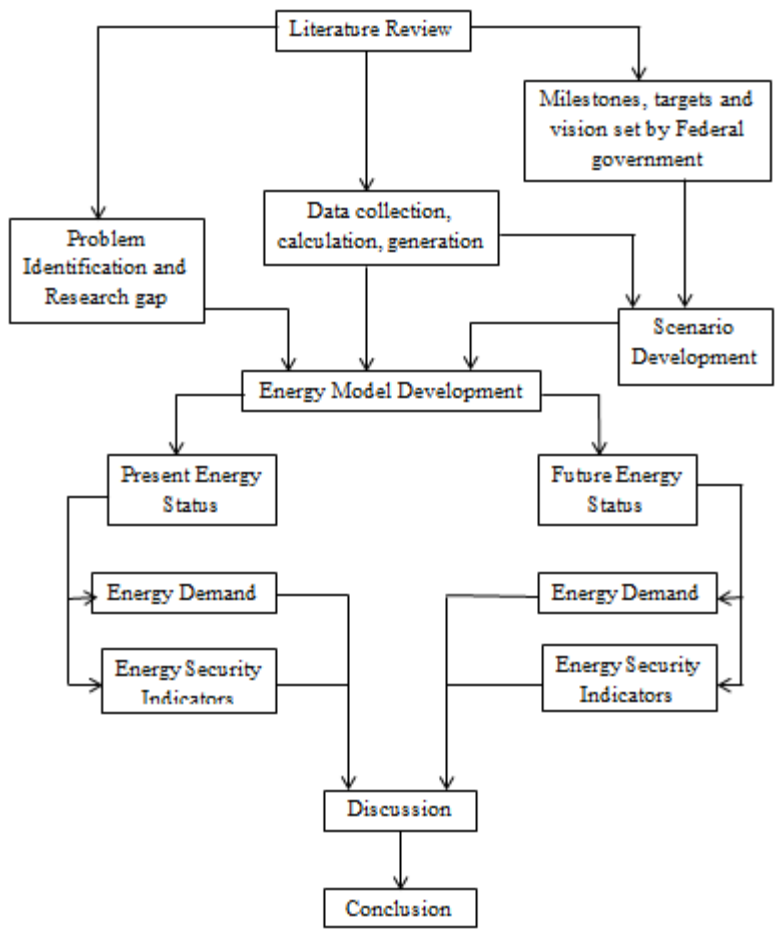

Figure 2: Methodological Flowchart of the Research

\subsection{Data Collection}

In order to know the present information on the energy mix of the Province One, the reports of various organizations were used for the reference. Since, most the data available online and in the publications, reports of the Government authorities and agencies, data of Nepal as a whole is generally presented, it's difficult to get the data information at the level of disaggregation from the government offices itself as required for this specific study purpose. However, the data obtained from the Alternative Energy Promotion Centre through their publications like District Climate and Energy Plan of various districts and the report of National Survey of Energy Consumption [4] were really helpful. Also, while creating the scenarios for the economic growth of the Province One in the study, the reports of Economic Survey [31,32] and also from the reports of Asian Development Outlook [33] were taken as reference.

The types of data collected are presented below:

- The demographic, political and geographical information of the province.

- Energy consumption at different disaggregation level possible. 
- Energy supply data from different government authorities

- Fuel prices projections

- GDP of Nepal and contribution from different sectors.

- Growth rate of GDP of Nepal in different point of times.

- GDP growth rate of South Asian countries at different point of time.

- GDP growth rate of Developing Asian Countries

\subsection{Modeling}

Long Range Energy Alternative Planning (LEAP), as defined by its creators, is an integrated, scenario-based modeling tool that can be used to track energy consumption, production and resource extraction in all sectors of an economy [34]. Also, the initial data requirements are quite low, which helps in getting the maximum insight despite having a low volume of data. Hence, a lot of future scenarios can be modeled on the basis of limited data and whose results can be used for gaining a better understanding of the interventions and policies undertaken. LEAP was used for generating the energy mix of the province for different scenarios developed. The software is easy to use and also the interface of the software enables the user to easily input data and generate scenarios.

In the Key Assumptions section of the LEAP Model, following parameters are used on the basis of data compilation obtained from Ministry of Finance [32] and Central Bureau of Statistics [35].

- Population: 4.707 Million

- Average Household Size: 4.63

- Number of Households

- GDP: 534.2 Billion NPR

- Share of Agriculture GDP: $48.31 \%$

- Share of Commercial GDP: $37.75 \%$

- Share of Industrial GDP: $13.94 \%$

For the input of data, a proper disaggregation level was used.

\subsection{Scenario Development}

Various documents and reports published by different organizations like World Bank, Asian Development Bank, Ministry of Finance, Nepal, Water and Energy Commission Secretariat (WECS) and Alternative Energy Promotion Centre (AEPC), etc. are taken as reference for the making different growth scenarios. Four different growth scenarios and one intervention sub scenario are used in the formulation of energy mix of the province. Normal economic growth scenario (NOR), Low economic growth scenario (LOW), High economic growth scenario (HIG), and Accelerated economic growth scenario (ACC) with economic growth rate of $5.80 \%, 4.20 \%, 4.50 \%$, $6.80 \%$, and $8.50 \%$ respectively are taken for the scenario building. And, an intervention sub scenario under Normal economic growth scenario (NOR) as the reference scenario, which mainly focuses on increasing the share of electricity in residential cooking, industrial boilers, heating and motive power, and transport sector $[2,3]$ is introduced in the normal economic growth scenario in order to see the effect of governmental interventions through policies and actions.

Table 1: GDP Growth Rates of Different regions in Asia (ADB, 2017 [33])

\begin{tabular}{|l|l|l|l|}
\hline \multirow{2}{*}{ Region/Country } & \multicolumn{3}{|l|}{ GDP Growth Rate } \\
\cline { 2 - 4 } & 2016 & 2017 & 2018 (Projected) \\
\hline Federal Asia & 2.2 & 3.3 & 3.9 \\
\hline East Asia & 6 & 6 & 5.8 \\
\hline South Asia & 6.7 & 6.7 & 7 \\
\hline Afghanistan & 2 & 2.5 & 3 \\
\hline Bangladesh & 7.1 & 7.2 & 6.9 \\
\hline Bhutan & 6.4 & 6.9 & 8 \\
\hline India & 7.1 & 7 & 7.4 \\
\hline Maldives & 3.4 & 4.2 & 4.4 \\
\hline Nepal & 0 & 6.9 & 4.7 \\
\hline Pakistan & 4.5 & 5.3 & 5.5 \\
\hline Sri Lanka & 4.4 & 4.5 & 5 \\
\hline Southeast Asia & 4.6 & 5 & 5.1 \\
\hline The Pacific & 2.4 & 2.9 & 3.2 \\
\hline Developing Asia & 5.8 & 5.9 & 5.8 \\
\hline $\begin{array}{l}\text { Developing Asia } \\
\text { excluding the NIEs }\end{array}$ & 6.3 & 6.4 & 6.3 \\
\hline
\end{tabular}

As per the Global Economic Prospects [36]

- The average GDP growth rate of a lower middleincome country is around $5.1 \%$.

- The average GDP per capita of a lower middleincome country is US\$2078.8.

- The average GDP growth rate of fastest growing economies like Bhutan, Ethiopia, Ghana, India, Myanmar, etc. in the recent years is around $8.5 \%$.

So, on the basis of different international reports and the reports of national governmental authorities, four different 
growth scenarios and one intervention scenario are used in the formulation of energy mix of the province.

Since Province One is one of the economically sound regions of the country, the economic growth of the province has to surpass the national average or at least equal the percentage change in economic growth of the Nepal as a whole in order to help the nation meet its targets.

Table 2: GDP Growth Rate of Nepal in Different Fiscal Years [32]

\begin{tabular}{|l|l|}
\hline Fiscal Year & GDP Growth Rate \\
\hline $2007 / 08$ & 5.8 \\
\hline $2008 / 09$ & 3.9 \\
\hline $2009 / 10$ & 4.26 \\
\hline $2010 / 11$ & 3.85 \\
\hline $2011 / 12$ & 4.61 \\
\hline $2012 / 13$ & 3.76 \\
\hline $2013 / 14$ & 5.72 \\
\hline $2014 / 15$ & 2.97 \\
\hline $2015 / 16$ & 0.01 \\
\hline $2016 / 17 \mathrm{P}$ & 6.94 \\
\hline
\end{tabular}

\subsubsection{Low Economic Growth Scenario (LOW)}

In this scenario the average economic growth rate of $4.5 \%$ is used. Since the country is catching the pace of reconstruction, the economic growth can be expected to increase a bit and at least be above the previous growth scenarios.

\subsubsection{High Economic Growth Scenario (HIG)}

In this scenario the economic growth of $6.8 \%$ is used. It is based on the average economic of South Asian countries [33]. Since, in case of proper development activities, it can be expected to match the growth of South Asian countries.

\subsubsection{Accelerated Growth Scenario (ACC)}

In this scenario the economic growth rate of $8.5 \%$ is used. It is based on the average GDP growth rates of the countries like Bhutan, Ethiopia, Ghana, India, Myanmar, etc. that are doing really well and making themselves recognized as the fastest growing economies of the world [36]. Since, there was election last year and the Left Alliance have got the majority in the parliament and which means that there will be a stable government for five continuous years in the federal and provincial level. If the stability helps the governments to work in full pace, then it won't be a hard nut to crack for the country itself and the provinces to realize that level of economic growth in the years to come.

\subsubsection{Normal Economic Growth Scenario (NOR)}

In this scenario the economic growth rate of $5.8 \%$ is used. It is based on the five years average GDP growth rates of Developing Asian countries [33]. Because of its realistic economic growth scenario, it is used as the most likely scenario for projecting the energy demand towards the end year.

\subsubsection{Intervention Scenario (INT)}

This scenario is developed in order to see the effect of policy interventions in the Normal Economic Growth Scenario (NOR). Interventions are used in every sector ranging from residential to agricultural sector of energy $\operatorname{mix}[2]$.

- Agriculture Sector: $100 \%$ electrification to be done in water pumping of agriculture sector by 2030 . Also, electrification in farm machinery to be increased to $25 \%$ by 2030 and $50 \%$ by 2050 .

- Commercial Sector :100\% electrification by 2030

- Transport Sector: Introduction of electric train in freight transport and its share is increased to $30 \%$ by 2050 , introduction of electric train in intercity transport and its share is assumed to be $30 \%$ by 2050 , electric car is introduced in the year 2020 to reach the target of $20 \%$ share by 2050

- Industrial Sector: Introduction of new electric boiler and share increased to $100 \%$ by 2050 , and $100 \%$ electrification in motive power by 2030

- Residential Sector: In cooking activity of rural area, fuel wise energy mix is $40 \%$ Electric, $50 \%$ Fuel wood and $10 \%$ LPG by 2030 . Similarly, ICS penetration with efficiency increased from $7 \%$ to $15 \%$ by 2030 . $100 \%$ electrification in cooking in urban area. $100 \%$ electrification by 2030 in space heating as well in urban area. Similarly, $40 \%$ electric, $50 \%$ fuel wood and $10 \%$ LPG fuel wise energy mix by 2030 in water heating in rural area. For water heating in urban area, share of solar thermal to $25 \%$ by 2030 and $100 \%$ electrification in the remaining water heating system. For miscellaneous activities in rural areas, the share of kerosene to zero percent by 2040 and ICS efficiency increased from $7 \%$ to $15 \%$. Meanwhile, for miscellaneous activities in urban area, $100 \%$ electrification by 2030 . For the lighting purpose in 
rural as well as urban areas, $100 \%$ electrification and use of LED by 2030.

\subsubsection{Selection of Reference Scenario among $B A U$ and NOR for carrying out the Intervention through INT Sub scenario}

For the Business as Usual scenario (BAU) the average economic growth rate of $4.2 \%$ needs to be used. And it is based on the value of average of economic growth rate of Nepal from 2007/08 to 2016/17. In this scenario, the end use technologies are unchanged.

Although National Accounts of Nepal [37] has predicted the economic growth rate of around $5.89 \%$ for the year $2017 / 18$, we haven't taken that growth rate directly for the BAU growth scenario. Since, due to the trend of unstable governments throughout the past decade the country haven't been able to realize a stable pace of economic growth. And also due to unfortunate incidents of earthquake in 2015 followed by border blockade in the recent years, the economic growth of the country has decreased drastically, thereby reducing the average economic growth of the past years to only $4.2 \%$.

And, now after the promulgation of new constitution followed by the formation of a stable government, the economy of the country can be most likely be expected to grow at least at the rate $5.8 \%$, which the CBS has predicted for the year 2017/18, now onwards on the ground of that stability. Hence, instead of BAU scenario, NOR economic growth scenario is used as the reference scenario for carrying out the interventions through INT sub scenario and for eventually calculating the energy security indicators in the end year.

\section{$4 \quad$ Result and Discussion}

\subsection{Energy Demand in different Scenarios}

The value of final total energy demand is different for the five scenarios used for projecting the energy mix towards the end year 2040. As we can see from the graph, if the province progresses with the accelerated economic growth then the energy demand will increase rapidly and be the highest among all other scenarios i.e. 124.8 Million GJ at the end year 2040 which is nearly $22.59 \%$ more than the energy demand which would have been in the end year in the case of NOR scenario growth. And, the lowest value of energy demand at the end year would be in the case of Intervention carried out in the Normal Growth scenario i.e. 86.8 Million GJ, which is nearly $14.73 \%$ less than the NOR growth case. Even though the growth rate in the
Intervention scenario is same to that of the normal economic growth scenario and much higher than the low economic growth scenario, the energy demand at the end year is significantly low than the both economic growth cases. This result can be explained on the basis of the introduction of energy efficient fuel-based technology interventions, eventually leading into the decrease in energy intensity.

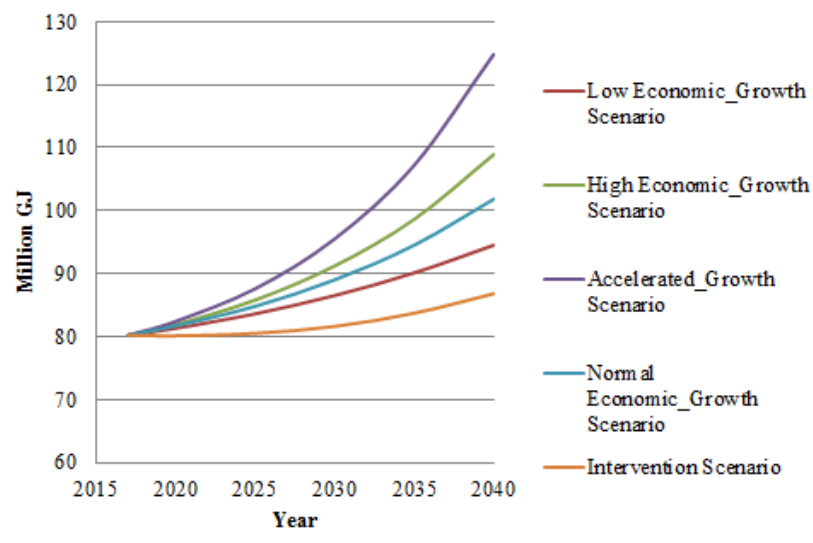

Figure 3: Overview of energy demand in different scenarios

\subsubsection{Energy Mix of End Year 2040 in NOR Scenario}

In the normal economic growth scenario, the total final energy demand increases by almost $27.34 \%$ and reaches 101.80 million GJ in the end year. Due to the good economic growth assumption, the share of industrial demand significantly increases from $6.32 \%$ to $18.16 \%$ towards the end year. Similarly, the growth in the share of commercial sector demand from $3.92 \%$ to $7.13 \%$ also accounts for the huge jump in total demand of the province in this particular scenario.

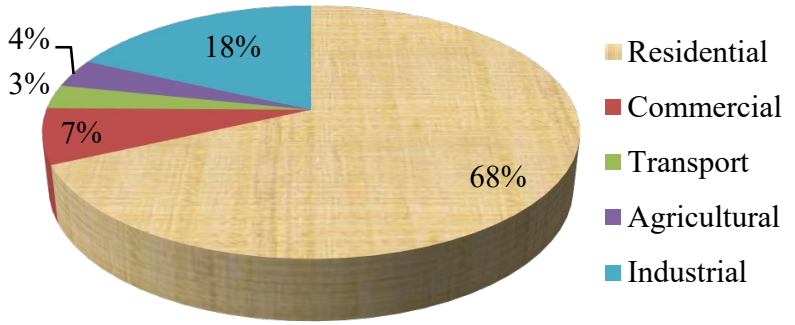

Figure 4: Sector wise Energy Mix of End Year 2040 in NOR Scenario

In the normal economic growth scenario, the share of fuel wood reduced to $64.87 \%$ from $73.53 \%$ in the end year. However, demand of diesel and coal significantly increased due to the growth of industrial sector resulting in the fuel share rise of diesel and coal i.e. $4.62 \%$ to $8.44 \%$ and $2.74 \%$ to $8.15 \%$ respectively. Similarly, the 
consumption of electricity has also increased by $120.10 \%$ and reached $256.88 \mathrm{kWh}$ per capita compared to the base year.

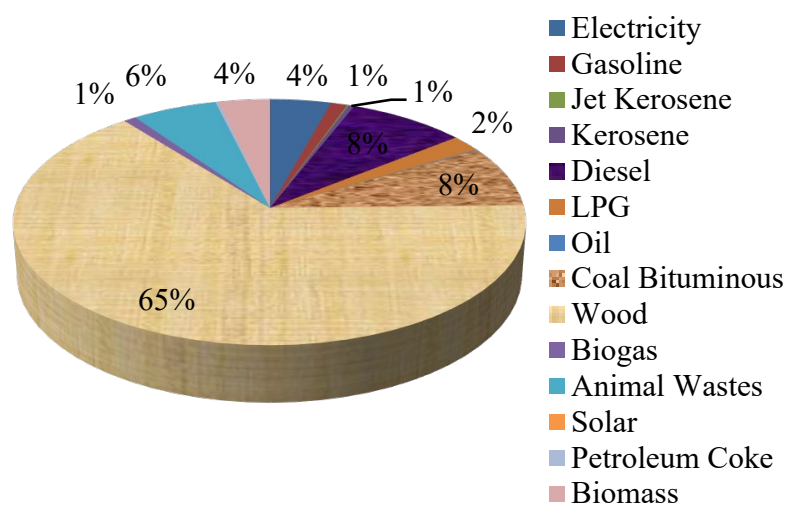

Figure 5: Fuel wise Energy Mix of End Year 2040 in NOR Scenario

\subsubsection{Energy Mix of End Year 2040 in INT Scenario}

In the intervention scenario, the total final energy demand increases by only $8.32 \%$ at the end year. And, due to the increase use of electricity in the residential sector for cooking and lighting instead of fuel wood and animal waste, the energy intensity in the residential sector is reduced significantly eventually resulting in the reduction of share of residential energy demand from $86.14 \%$ to $68.21 \%$ in the total energy mix.

In the intervention scenario, the share of electricity has increased drastically from $2.51 \%$ to $11.33 \%$ in the end year. However, the share of diesel is not so high in the end year as compared to the normal economic growth without intervention. But, in contrast the consumption of electricity has increased by $390.21 \%$ and reached 574.13 $\mathrm{kWh}$ per capita in the end year. And, the possible reason for this is the introduction of electric boilers, electric motive powers in industries and also the increased use of electrical appliances for cooking and heating purposes in the residential sector.

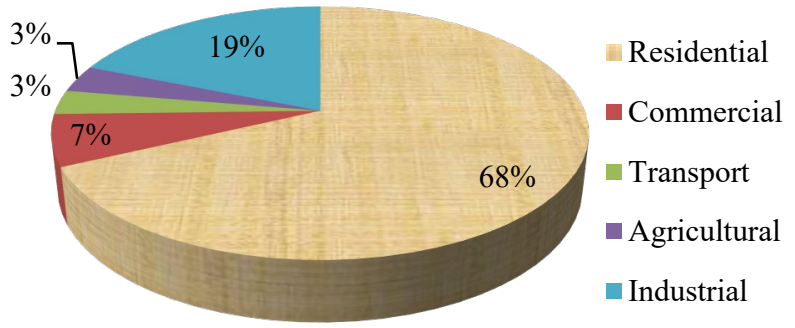

Figure 6: Sector wise Energy Mix of End Year 2040 in INT Scenario

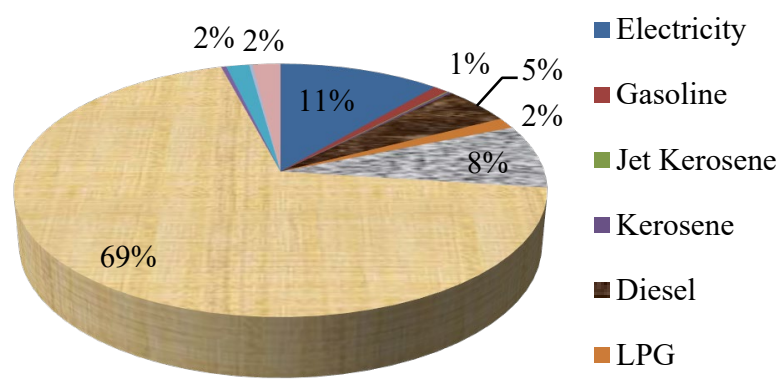

Figure 7: Fuel wise Energy Mix of End Year 2040 in INT Scenario

\subsection{Energy Security Indicators}

\subsubsection{Overview of Energy Security Indicators in Base Year and End Year}

The value of final energy consumption per capita is 18.19 GJ in the base year 2017. And, it is increased to $21.53 \mathrm{GJ}$ in the year 2040 under normal growth scenario. However, the value is lower after intervention compared to the stand alone NOR scenario i.e. 18.35 GJ.

Similarly, the value of electricity consumption per capita is $116.16 \mathrm{kWh}$ in the base year 2017. And, it is increased to $256.88 \mathrm{kWh}$ in the year 2040 under normal growth scenario. However, the value is nearly doubled after intervention compared to the stand alone NOR scenario i.e. $574 \mathrm{kWh}$.

The two energy security indicator graphs (figure 8 and 9) explain how the consumption of energy and electricity per capita varies while moving towards the end year in two different scenarios. The figure 8 shows that the energy consumption per capita increases in the normal economic growth scenario. However, it tends to remain the same in the case of intervention scenario because of the increased use of more efficient fuels like electricity in the industrial as well as the residential sectors. Similarly, introduction of electric trains and buses for the freight and passenger transport, and total electrification in commercial sector, etc. increased the Electricity Consumption Per Capita in the Intervention scenario in contrast to the Normal growth scenario.

In the figure 10, the graph shows the trend of variation of energy intensity in the normal growth scenario, with and without interventions. The value of energy intensity is $15.00 \mathrm{GJ} / \$ 1000$ in the base year 2017. And, it is decreased to $5.21 \mathrm{GJ} / \$ 1000$ in the year 2040 under normal growth scenario. However, the value is further lowered after intervention compared to the stand alone NOR scenario i.e. $4.44 \mathrm{GJ} / \$ 1000$. 
Table 3: Values of Energy Security Indicators

\begin{tabular}{|c|c|c|c|c|}
\hline Indicators & Unit & Base Year & End Year (NOR) & End Year (INT) \\
\hline Final Energy Consumption Per Capita & (GJ/Capita) & 18.19 & 21.53 & 18.35 \\
\hline Electricity Consumption per Capita (KWh/Capita) & (KWh/Capita) & 116.6 & 256.88 & 574.1 \\
\hline Energy Intensity & $(\mathrm{GJ} / \$ 1000)$ & 15 & 5.21 & 4.44 \\
\hline Electricity Intensity & $(\mathrm{KWh} / \$ 1000)$ & 102.8 & 62.2 & 138.95 \\
\hline Electricity Power Utilized & (Percent) & 70.49 & 11.37 & 25.42 \\
\hline $\begin{array}{l}\text { Total Energy Consumption/Value added } \\
\text { in Industrial Sector }\end{array}$ & $\begin{array}{l}(\mathrm{GJ} / \$ 1000 \\
\text { Value added })\end{array}$ & 6.71 & 6.76 & 6.02 \\
\hline Total Energy Used/ Household & $(\mathrm{GJ} / \mathrm{HH})$ & 78.86 & 99.7 & 85.01 \\
\hline Share of renewable energy in final total energy consumption & (Percent) & 89.1 & 79.6 & 83.98 \\
\hline $\begin{array}{l}\text { GHG emission for every ton of energy } \\
\text { production and use/capita }\end{array}$ & $\begin{array}{l}\text { (GHG in } \\
\text { Kg/Capita) }\end{array}$ & 371.8 & 592.8 & 385.2 \\
\hline Ratio of value if oil imports to GDP & & 0.11 & 0.088 & 0.048 \\
\hline Oil consumption per unit GDP in USD & GJ/GDP & 0.012 & 0.0065 & 0.0035 \\
\hline Oil Share in total energy supply & Percent & 7.98 & 12.38 & 7.83 \\
\hline Net energy import ratio (NEIR) & & 0.1 & -0.13 & -0.17 \\
\hline Oil consumption per capita (OCPC) & GJ/Capita & 1.36 & 2.66 & 1.44 \\
\hline Net Oil Import Dependency (NOID) & & 1 & 1 & 1 \\
\hline Shannon-Wiener Index (SWI) & & 1.101 & 1.341 & 1.160 \\
\hline
\end{tabular}

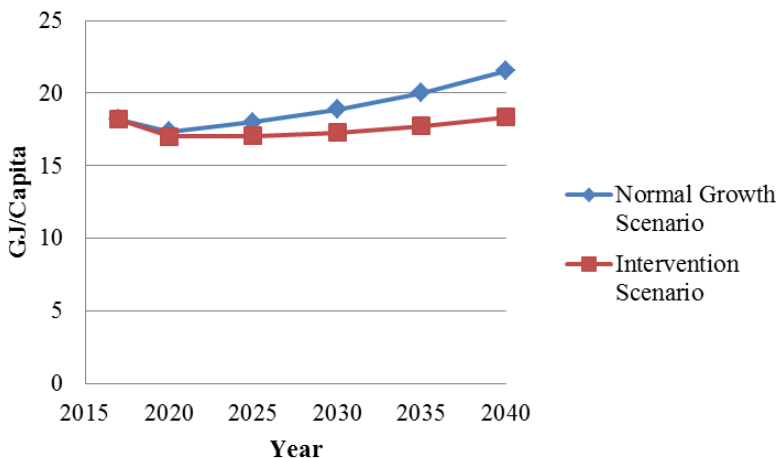

Figure 8: Final energy consumption per capita in two different scenarios

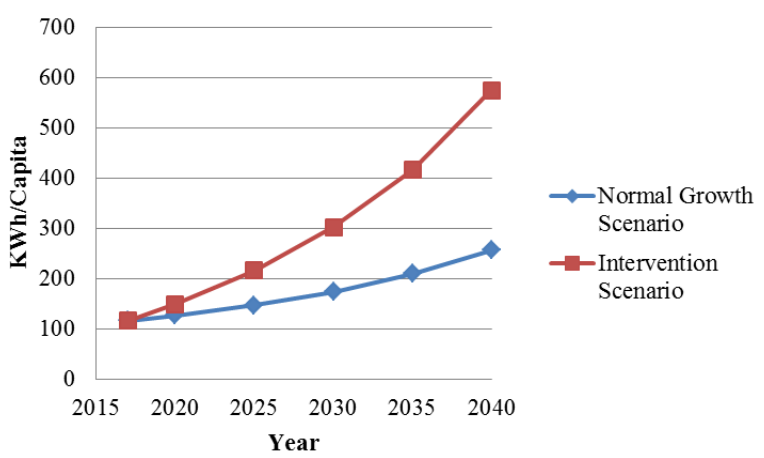

Figure 9: Electricity consumption per capita in two different scenarios

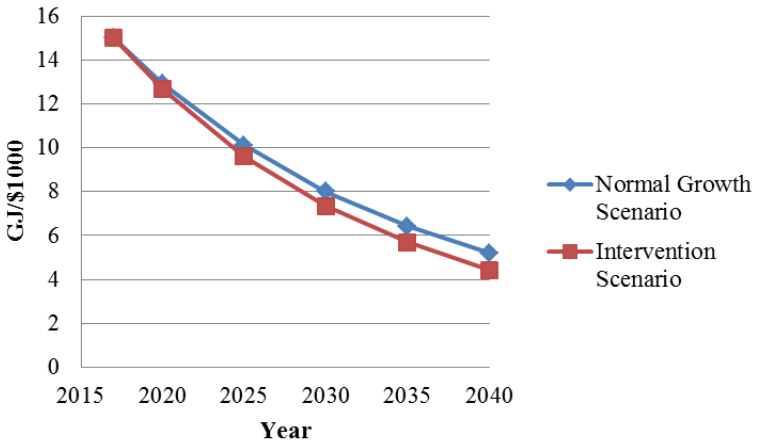

Figure 10: Energy Intensity in two different scenarios

The figure 11 shows the variation of electricity intensity in the normal economic growth scenario, with and without the policy intervention. The value of electricity intensity is $102.80 \mathrm{kWh} / \$ 1000$ in the base year 2017 .

And, it is decreased to $62.20 \mathrm{kWh} / \$ 1000$ in the year 2040 under normal growth scenario. However, the value is further increased after intervention compared to the stand alone NOR scenario i.e. $138.95 \mathrm{kWh} / \$ 1000$.

In the figure 12 , the graph shows the trend of utilization of electric power available in the province in the normal growth scenario, with and without interventions. The value of Electricity utilization in the base year 2017 is $70.49 \%$. And, it is decreased to $11.37 \%$ in the year 2040 
under normal growth scenario. However, the value is higher after intervention compared to the NOR scenario i.e. $25.42 \%$.

In the graph, the utilization of electricity is quite high in the start however, around 700MW of hydropower plants are expected to be completed and connected to the grid in between 2020-2025 and another 800MW of hydropower plants are expected to be completed and connected in the grid after 2025 resulting in the underutilization due to excess production of electricity in the province.

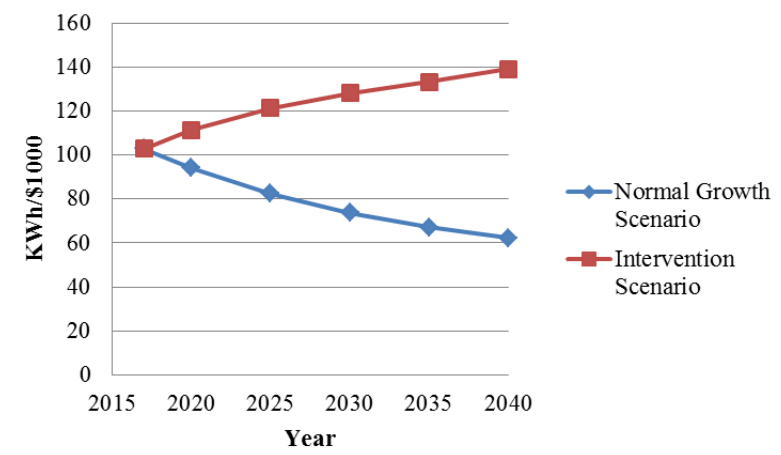

Figure 11: Electricity Intensity in two different scenarios

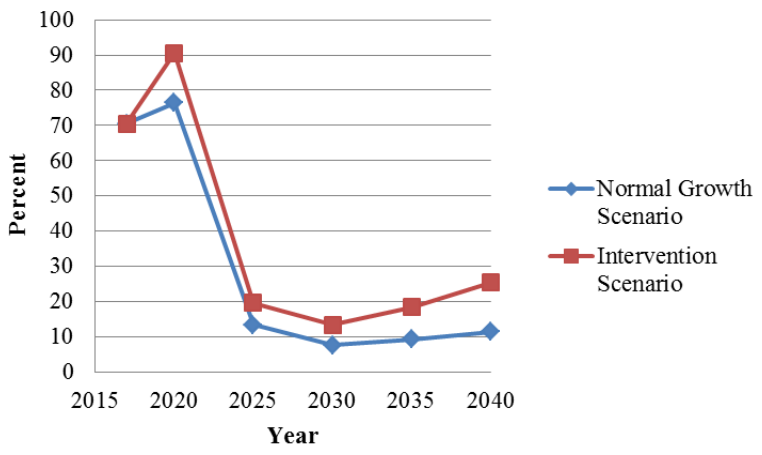

Figure 12: Electricity Power utilized in two different scenarios

Figure 13 shows the variation in the share of renewable energy (excluding traditional biomass) in the total energy/fuel mix towards the end year in the normal economic growth scenario, with and without policy interventions. The value of share of renewables is $3.56 \%$ in the base year 2017. And, it is increased to $5.16 \%$ in the year 2040 under normal growth scenario. However, the value is increased after intervention compared to the stand alone NOR scenario and reaches $11.56 \%$ in the end year.

The figure 13 shows that the share of renewable energy doesn't increase much i.e. only increase to $5.16 \%$ in end year from $3.56 \%$ of base year in the normal growth scenario. Because of continuation in the consumption of fossil fuels in same pace in the industrial and transport sector, the share of oil consumption maintains its demand resulting in only a slight increase in share of renewables. However, in the intervention scenario, due to the introduction and increased use of electric boilers, electric motive powers, electric heating, there is reduction in the use of fossil fuels as compared to the normal growth scenario, which help in doubling the share of renewables to $11.56 \%$ in the end year.

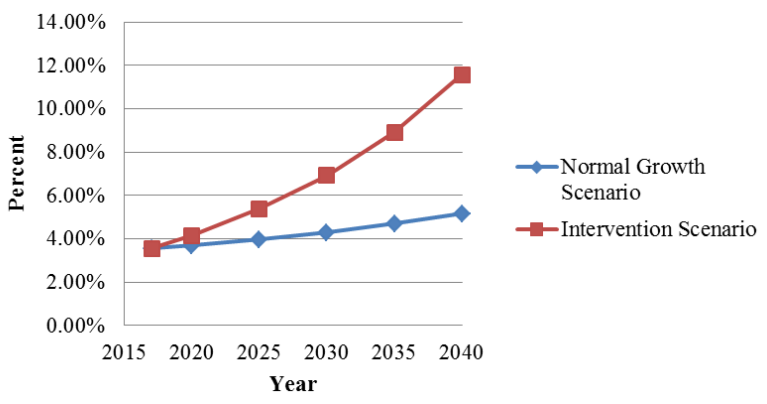

Figure 13: Share of Renewable energy in total energy consumption

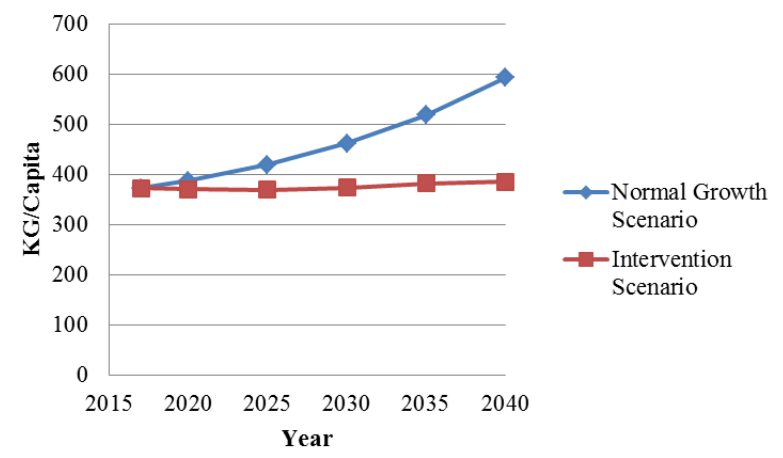

Figure 14: GHG emission in energy use per capita in two different scenarios

The figure 14 shows the variation of GHG emission in the Normal economic growth scenario, with and without intervention towards the end year. The value of GHG emission in energy use per capita is $371.80 \mathrm{~kg}$ in the base year 2017. And, it is increased to $592.80 \mathrm{~kg}$ in the year 2040 under normal growth scenario. However, the value is lower after intervention compared to the NOR scenario i.e. $385.20 \mathrm{~kg}$ towards the end year.

This graph is directly related to the Energy Consumption Per Capita and thus shows the similar pattern. In normal growth scenario, due to the increase in the Energy Consumption Per Capita, the emission also increases in the similar manner. And, in the intervention scenario, due to the increased use of efficient renewable fuels i.e. electric stoves, Improved Cooking Stove, electric space heating, etc. the GHG emission is maintained.

As of today, around $11.10 \%$ of the GDP is expended in importing Oil for meeting the $8.00 \%$ of the energy 
demand of the province. In the Normal growth scenario, the value is still around $9.12 \%$. Thus, the problem that can arise due to import dependency is minimal in the intervention scenario in which only $5.00 \%$ of the GDP is expended in end year for importing expensive oils by maintaining a good share of renewables in the fuel mix.

The figure 16 shows the variation of Oil Consumption per GDP in the normal economic growth scenario, with and without intervention towards the end year. The value of Oil Consumption per GDP (\$) is $0.012 \mathrm{GJ}$ in the base year 2017. And, it is decreased to 0.0065 GJ in the year 2040 under normal growth scenario. However, the value is lower after intervention compared to the NOR scenario i.e. $0.0035 \mathrm{GJ}$ towards the end year.

The figure 17 shows the variation of oil share in the total energy supply in the normal economic growth scenario, with and without intervention. The value of oil share is $7.98 \%$ in the base year 2017. And, it is increased to $12.38 \%$ in the year 2040 under normal growth scenario. However, the value is lower after intervention compared to the NOR scenario i.e. $7.83 \%$ towards the end year 2040.

The figure 18 shows the variation in the value of Net Energy Import Ratio in the Normal economic growth scenario, with and without interventions. The value NEIR is 0.10 in the base year 2017. And, it is decreased to -0.13 in the year 2040 under normal growth scenario. And, the value is further lowered after intervention compared to the stand alone NOR scenario i.e. -0.17.

It can be seen in the graph that the, value is in the positive axis until 2025 and goes to the negative side after 2025 . Here, the positive value indicates that the region is an energy importer whereas; the negative value suggests that the region is an energy exporter. Thus, due to the expected addition of about $700 \mathrm{MW}$ hydropower in the grid in between 2020 to 2025, the province slowly transforms into the energy exporter. However, the exporting value starts to move towards zero after 2030due to the increased consumption of electricity in the province resulting in less availability of exportable electricity.

The figure 19 shows the variation of Oil Consumption Per Capita in the Normal growth scenario, with and without intervention in the end year. The value of Oil Consumption Per Capita is 1.36 GJ in the base year 2017. And, it is increased to $2.66 \mathrm{GJ}$ in the year 2040 under Normal growth scenario. However, the value is lower after intervention compared to the stand alone NOR scenario i.e. 1.44 GJ per capita.

The figure 20 shows the variation of Shannon-Weiner index in normal economic growth scenario, with and

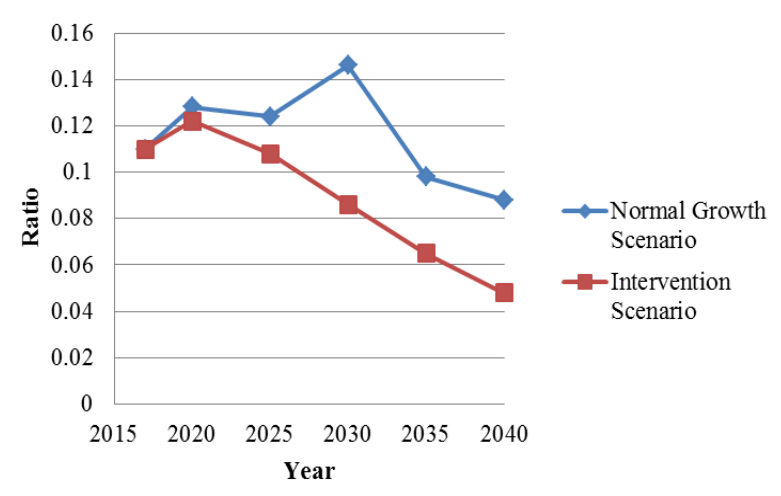

Figure 15: Ratio of value of oil imports to GDP in two different scenarios

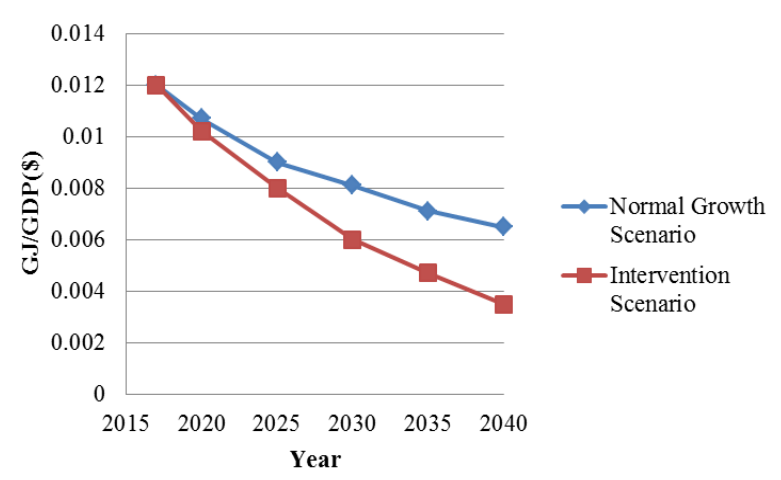

Figure 16: Oil Consumption per unit GDP (\$) in two different scenarios

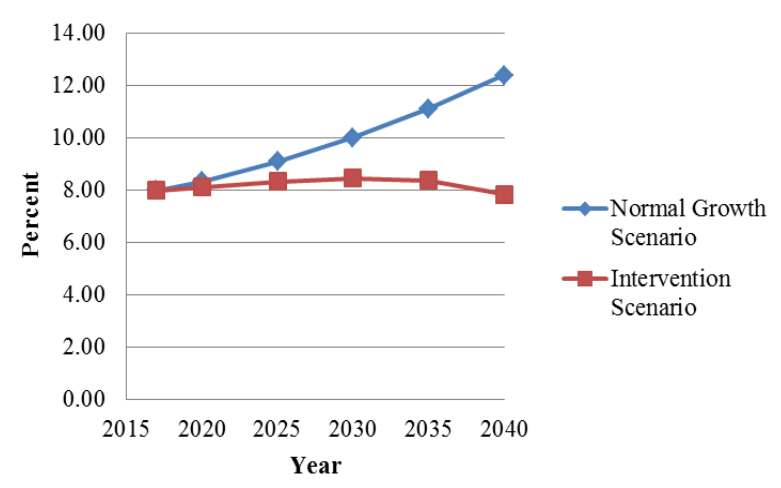

Figure 17: Oil share in total energy supply in two different scenarios

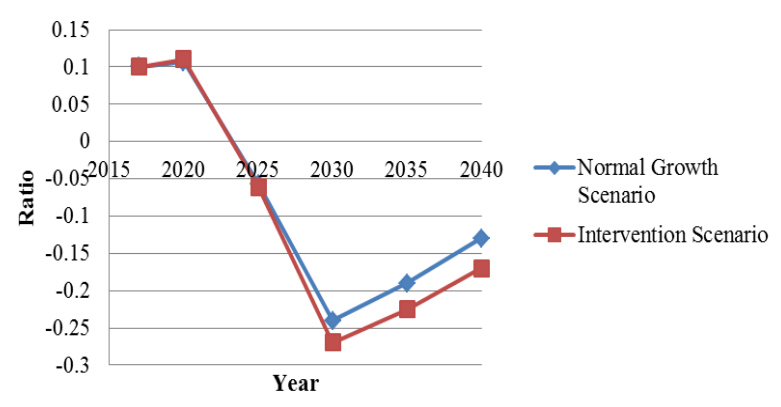

Figure 18: Net Energy Import Ratio (NEIR) in two different scenarios 
without intervention. The value of SWI is 1.101 in the base year 2017. And, it is increased to 1.341 in the year 2040 under normal growth scenario. However, the value is lower after intervention compared to the stand alone NOR scenario i.e. 1.116.

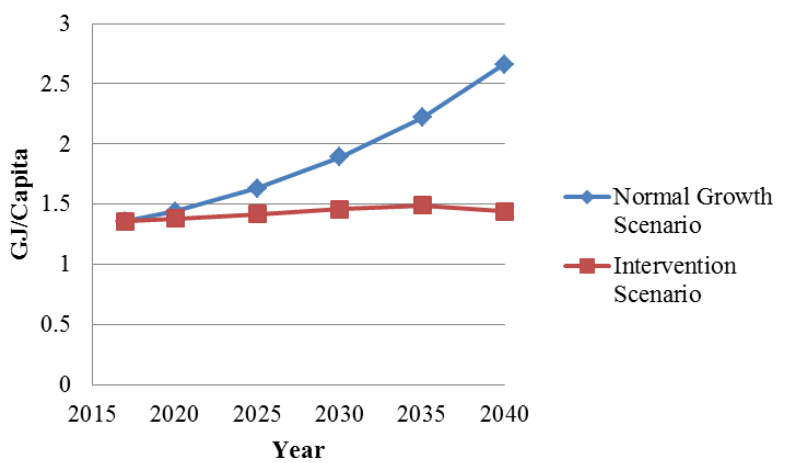

Figure 19: Oil consumption per capita in two different scenarios

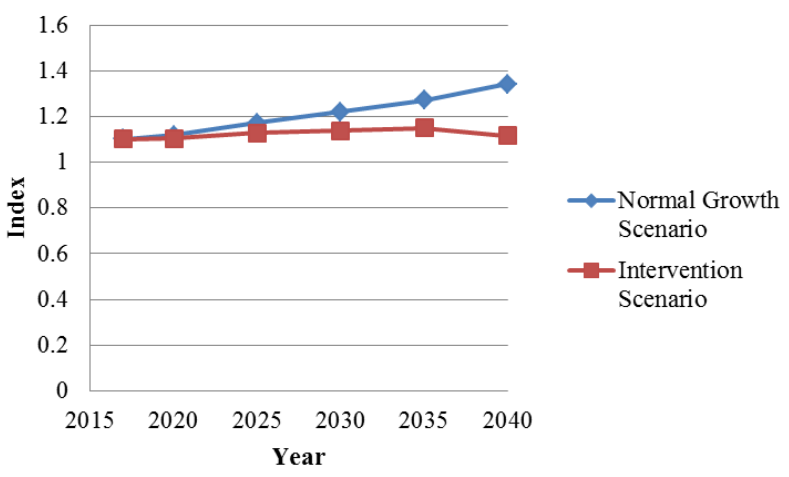

Figure 20: Shannon-Weiner Index (SWI) in two different scenarios

Shannon-Weiner Index in the above graph indicates about the diversity of fuels/resources in the province. Greater the value of SWI, higher is the energy security of the region. In contrast to the increasing value of SWI for normal growth scenario, the diversity of the fuel is not improved in intervention scenario due to increased use of electricity and decreased use of fossil fuels. Although, the intervention scenario has better numbers and values in other energy security indicators, for the case of diversity of fuels, normal growth scenario is slightly better.

\subsection{Discussion}

The results of energy mix and energy indicator values obtained for Province One for the base year 2017 and its variation/progression towards end year 2040 are first of its kind, so the results obtained couldn't be compared with the past data of the province itself. However, results obtained are compared with the data of Nepal, India, China, Asian average and the World average.
If we compare the fuel wise energy mix of the province with the national mix, the share of renewable energy resource is almost same in both the cases i.e. $3.56 \%$ in province level and 3.5\% in national level [32]. Due to the extensive use of fuel wood and other biomass for cooking and heating purposes in residential sector throughout the country, fuel wood has the largest share in the fuel mix in both province and national level, and residential sector also being the largest energy consuming sector in national level as well. However, if we see the energy consumption in China, coal, oil and hydro have shares of $63.7 \% 18.6 \%$ and $8.5 \%$ respectively [38]. This is due to the largest share of industrial consumption, which is mostly fueled by coal and oil. In the global energy consumption, oil has the highest share i.e. $33 \%$ followed by coal and natural gas i.e. $28 \%$ and $24 \%$ respectively $[27,28]$.

At the present context, the energy consumption per capita of Province One i.e. 18.19 GJ is slightly higher than that of the national average of 17.15 GJ. However, when compared to the world average, the value is 4.3 times lower. The electricity consumption per capita of the province i.e. $116.6 \mathrm{kWh}$ is $16.7 \%$ lower than the national average of $140 \mathrm{kWh}$. When compared to the other economies like India, which has $860 \mathrm{kWh}$ per capita of electricity consumption, the value is $86.4 \%$ lower $[27,28]$. Similarly, the value of province is $96.1 \%$ lower than the world average electricity consumption per capita. However, in the end year of intervention scenario, the electricity consumption per capita improves by about five times and reaches around $68 \%$ of the value India has in this present context.

When comparing the GHG emission per capita in the province, it is 1.7 times higher than the national average of $200 \mathrm{~kg}$ per capita. However, it is 12 times less than the world average of $4400 \mathrm{~kg}$ per capita. And, regarding the energy import status of the province, it is only $10 \%$ compared to that of $17 \%$ of the national average value and $21 \%$ of the world average $[27,28]$.

There is a drastic difference in the values obtained for province when compared with the values of other countries, regions and the world. The energy mix of any region is hugely affected by the nature of economy, its geography i.e. island, landlocked, etc., and also on the availability of the indigenous resources they have within their territory. So, in order to achieve energy security, the regions devise the policies so as to promote the use of technologies that run on the indigenous resources and on the controllable energy sources. Thus, the policies and priorities differ from country to country and region to region. In case of Pakistan, although it has huge reserves 
of crude oils and coal, the new renewable energy policy framed in 2011 has planned to green Pakistan concept by promoting hydroelectric powers for a sustainable development [10]. Similarly, the recent energy strategy plan in Japan prioritizes energy security, but it also considers economic efficiency and the conservation of the environment, all with a strong focus on safety $(3 \mathrm{E}+\mathrm{S})$. They have also started to see human security as also a part of achieving energy security following the Fukushima Nuclear Plant disaster [11]. In 2009, China, for the first time, translated into a net importer of coal, and the dependency of oil import was about 53\%. In 2013, the proportion of oil import and natural gas import reached $58.9 \%$ and $27.6 \%$, respectively [17]. The Twelfth FiveYear Plan for National Strategic Emerging Industries Development has outlined renewable energy industry as one of the key strategic emerging industries. This is to say that renewable energy will become the new source of economic growth in China. Similarly, it has also closed down thousands of MW capacity of outdated thermal plants in an effort to increase the energy efficiency. Similarly, Top runner program introduced in Japan in 1999 played an important role for encouraging companies to aim for energy efficiency. The government labeled the products in terms of energy efficiency and also awarded the products and companies, who actually energy efficiently produced their products [18]. Thus, for gaining the fame, most companies and industries marched in the path of energy efficiency.

Thus, the main focus of the regions should be in three areas of vulnerability, efficiency and sustainability in order to achieve energy security.

\section{Conclusion}

The energy demand of the Province One is expected to reach a value of 101.20 Million GJ at 2040 in Normal economic growth scenario which is about $27.00 \%$ increase from the base year (2017) energy consumption of 80.2 Million GJ. Although the increase in the demand is not that huge, the sector wise energy demand shows the decrease in the share of the largest energy consuming sector i.e. Residential from $86.11 \%$ to $68.10 \%$. Moreover, due to the rapid economic growth, share of sectors, other than residential and transport have increased significantly by three and half folds, thereby increasing the fuel share of electricity and petroleum by 1.5 and 2.5 folds respectively towards the end year.

However, with the intervention in the Normal economic growth scenario, the energy demand of the province can be significantly lowered to 86.8 Million GJ, which is just
$8 \%$ increase from the base year value. And, the demand of electricity in the fuel mix can be increased by five times in contrast to only 1.2 times from the base year.

Thus, with the proper implementation of plans of increasing the share of electricity in residential cooking, heating, industrial boiler, motive power, and transport, the energy intensity can be significantly lowered, which will eventually help to reduce the expending share of GDP from $11 \%$ to $4 \%$ for imported fuels towards the end year.

Since the province has the ability to be an energy exporter in the near future, with huge contribution for hydropower development projects, it is high time for the provincial government to facilitate the people to increase the use of electric appliances for the residential purposes rather than the fossil fuel and biomass, fuel wood alternatives. The government can also, provide special tax benefits for the energy efficient and electricity driven technologies in order to increase the electricity utilization index from $11 \%$ to $25.4 \%$

Moreover, it will also help the provincial government to maintain the double the share of renewable energy in the mix in compliance to the target of Sustainable energy for all initiative, thereby limiting the growth of Greenhouse gas emission per capita by only $8 \%$ in contrast to $59 \%$ in the Normal growth scenario, which in the long run helps government to contribute towards the sustainable development goals. The Net Energy Import Ratio indicator of the province also changes from a positive value of 0.1 to a negative value of -0.17 indicating the switch from an energy importing to an energy exporting region Hence, the province has the capacity to shift itself towards energy exporting region from the energy importing region in the coming seven years and can generate revenue up to NPR 39 billion (current price) yearly from the energy trade. And this strengthens the provinces economy as an energy secured and a selfsustainable region.

From the effect that we observed from the policy intervention done in the scenario development, it is evident that if the type of policies envisioned in the federal level vision documents be properly implemented in the provincial level as well, then the issue of energy security is heavily strengthened.

\section{Recommendation}

On the basis of findings and discussions on the evolution of energy demand from base year towards the end year, there are some recommendations for the policy interventions and possibilities of further study. 
The provincial government should have a proper realization of its indigenous resources and eventually mainly focus in three areas of vulnerability, efficiency and sustainability in order to achieve energy security. The government should put an effort on the diversification of energy resources in order to hedge against the price fluctuations and threats of supply disruption. Similarly, increasing the share of energy consumption from the controllable energy resources should be the top most priority in order for the energy securement. It means, utilizing the indigenous resources to the maximum extent possible like, hydroelectricity, solar, etc. Also, maintaining source of supply of imported fuels from different regions, in order to hedge the risk of supply disruption. Although, securing supply is considered to be the main aspect of energy security, efficiency and demand side management is an important aspect of supporting any region for the energy security. The policy similar to that of Japan called "Top Runner Programme" can be introduced in the province in coordination with the federal government. That program initiated in 1999, is a set of energy efficiency standards for energy intensive products, such as home appliances and motor vehicles. Energy efficiency targets are set to be achieved within a given number of years on the basis of the most efficient model on the market. Products which do meet the energy efficiency standard receive a Top Runner label at the point of sale; those which do not are labelled differently. This drives companies to try to make ever more efficient models to compete for the award of Japan's 'Top Runner'. The Minister of the Environment (METI) can disclose the names of companies that fail to meet the targets, as well as issue recommendations, orders and fines. This also drives companies to avoid negative publicity. Similarly, on the consumer end, the government also has to encourage the general people to use energy efficient technologies. Renewable energy resources use should drive the economy of the region because renewable energy is not only a sustainable choice of clean energy system, but also as an approach to addressing other social pressing needs, including improving energy security, reducing environmental impacts associated with fossil fuel consumption, as well as mitigating climate change.

Thus provincial government should extensively promote the use of energy efficient technologies. For e.g., electric cooking and ICS, LED lighting, etc. in residential sector in order to decrease the energy intensity of the province, thereby helping in demand side energy management of the energy. Moreover, the provincial government along with the help of federal government can introduce the policy of tax benefits or subsidies for using energy efficient technologies.

The government can encourage the industries to introduce the electric boilers and electric power motives in order to significantly lower the dependence on imported fossil fuels and eventually reduce the GHG emissions. It can be also be done by providing tax benefits to the industries switching to electric appliances in replacement of fossil fuel based ones. Similarly, the government should also encourage private sectors to invest in electric vehicles in the transport sector. This can be done by collaborating with the federal government on subsidizing the customs of electric vehicles, and also reduced road taxes, priority services, free parking's, etc.

The benefit of utilizing the energy source within the region adds much more value in terms of the GDP growth of the region, then just merely by selling it. Moreover, the increase in the utilization index through establishment of new businesses and industries will eventually increase the employment opportunities and also the rise in the economic activities in the region resulting in the holistic development of the province. Thus, the provincial government should prioritize the policy of increasing the consumption of electricity within the province.

Since, this study helps to give the status of energy scenario of the province, similar type of studies can be carried out in the context of other provinces as well for having a better indication on the energy security status of those provinces. Furthermore, other authors can add the cost component to this study to have a further understanding on the economics aspect of achieving the energy security and sustainability of the province.

\section{Acknowledgments}

The authors are thankful to the Department of Mechanical Engineering on Institute of Engineering, Pulchowk Campus for the research opportunity. The authors would also like to acknowledge the support of Water and Energy Commission Secretariat for their help in obtaining the data for conducting the research.

\section{References}

[1] Constituent Assembly, "Constitution of Nepal," Nepal Government, 2015.

[2] Water and Energy Commission Secretariat, "Nepal's Energy Sector Vision 2050," Kathmandu, 2013. 
Energy Security and Scenario Analysis of Province One of Federal Democratic Republic of Nepal

[3] Water and Energy Commission Secretariat, "National Energy Strategy of Nepal," Kathmandu, 2013.

[4] Water and Energy Commission Secretariat, "National Survey of Energy Consumption and Supply Situation in Nepal," Kathmandu, 2013.

[5] Investment Board of Nepal, "Energy Demand Projection:A MAED Based Approach," Kathmandu, 2015.

[6] Water and Energy Commision Secretariat, "Electricity Demand Forecast Report," Kathmandu, 2017.

[7] Alternative Energy Promotion Centre (AEPC), "District Climate and Energy Plan, Sunsari," 2014.

[8] W. Lu and M. Su, "Energy security assessment: A review," Advanced Materials Research Vols. 724-725, pp. 1211-1215, 2013.

[9] International Energy Agency, "The IEA Model of Short Term Energy Security," 2011.

[10] T. Aized, M. Shahid, A. A. Bhatti, M. Saleem and G. Anandarajah, "Energy security and renewable energy policy analysis of Pakistan," Renewable and Sustainable Energy Reviews, 84, pp. 155-169, 2018.

[11] K. Matsumoto and H. Shiraki, "Energy security performance in Japan under different socioeconomic and energy conditions," Renewable and Sustainable Energy Reviews, 90, pp. 391-401, 2018.

[12] T. Kitamuraa and S. Managi, "Energy security and potential supply disruption: A case study in Japan," Energy Policy,110, pp. 90-104, 2017.

[13] Q. F. Erahman, W. W. Purwanto, M. Sudibandriyo and A. Hidayatno, "An assessment of Indonesia's energy security index and comparison with seventy countries," Energy, 111, pp. 364-376, 2016.

[14] B. K. Sovacool, I. Mukherjee, I. M. Drupady and A. L. D'Agostino, "Evaluating energy security performance from 1990 to 2010 for eighteen countries," Energy,36, pp. 5846-5853, 2011.

[15] E. Kisel, A. Hamburg, M. Härm, A. Leppiman and M. Ots, "Concept for Energy Security Matrix," Energy Policy, 19, pp. 1-9, 2016.

[16] J. Martchamadol and S. Kumar, "The Aggregated Energy Security Performance Indicator (AESPI) at national and provincial level," Applied Energy, 127, pp. 219-238, 2014.

[17] B. Wanga, Q. Wang, Y. M. Wei and Z. P. Li, "Role of renewable energy in China's energy security and climate change mitigation: An index decomposition analysis,"
Renewable and Sustainable Energy Reviews, 90, pp. 187-194, 2018.

[18] L. Yao, X. Shi and P. Andrews-Speed, "Conceptualization of energy security in resource-poor economies: The role of the nature of economy," Energy Policy, 114, pp. 394-402, 2018.

[19] K. Kanchana and H. Unesaki, "ASEAN Energy Security:An indicator-based assessment," in 11th EcoEnergy and Materials Science and Engineering, 2014.

[20] A. M. Nakarmi, T. Mishra and R. Banerjee, "Integrated MAED-MARKAL-based analysis of future energy scenarios of Nepal," International Journal of Sustainable Energy, p. DOI:10.1080/14786451.2014.966712, 2014.

[21] A. M. N. Utsav Shree Rajbhandari, "Energy Consumption and Scenario Analysis of Residential Sector Using Optimization Model- A Case of Kathmandu Valley," in IOE Graduate Conference, 2014.

[22] S. R. Shakya and R. M. Shrestha, "Transport sector electrification in a hydropower resource rich developing country:," Energy For Sustainable Development, 2011.

[23] B. Kruyt, D. v. Vuuren, H. de Vries and H. Groenenberg, "Indicators for energy security," Energy Policy, p. 21662181, 2009.

[24] J. Martchamadol and S. Kumar, "Thailand's energy security indicators," Renewable and Sustainable Energy Reviews, p. 6103-6122, 2012.

[25] Asia Pacific Energy Research Centre, "A QUEST FOR ENERGY SECURITY IN 21ST CENTURY: RESOURCES AND CONSTRAINTS," 2007.

[26] United Nations, "Transforming our world:The 2030 Agenda for Sustainable Development," 2015.

[27] International Energy Agency, "Statistics: Statistics Search," [Online]. Available:

https://www.iea.org/statistics/statisticssearch/. [Accessed 15 April 2018].

[28] International Energy Agency, "Topics: Energy Security," [Online]. [Accessed 6 January 2018].

[29] Nepal Oil Corporation, "Annual Report," 2017.

[30] Nepal Electricity Authority, "Annual Report," 2017.

[31] Ministry of Finance, Nepal, "Economic Survey," 2016.

[32] Ministry of Finance, Nepal, "Economic Survey," 2017.

[33] Asian Development Bank, "Asian Development Outlook," 2017. 
[34] Stoclkhom Environment Institute, "About: Introduction," [Online]. Available: https://www.energycommunity.org/default.asp?action=in troduction. [Accessed 0501 2018].

[35] Central Bureau of Statistics, "National Population and Housing Census," 2011.

[36] World Bank Group, "Global Economic Prospects," 2017.

[37] Central Bureau of Statistics, "National Accounts of Nepal 2017/18," 2018.

[38] China Energy Group, "Key China Energy Statistics," 2016.

[39] International Energy Agency, "Topics: Energy Security," [Online]. Available:

https://www.iea.org/topics/energysecurity/. [Accessed 6 January 2018]. 